\title{
Orthodontics and enamel spots. Benefits of a minimally invasive approach, suidelines for the orthodontist
}

\author{
A. Atlan ${ }^{1}$, M. Denis ${ }^{2}$, G. Tirlet ${ }^{3}$, J.-P. Attal ${ }^{4}$ \\ 1 Former University Hospital Lecturer, Paris Descartes, Private practice, Paris \\ 2 Former University Hospital Lecturer, Paris Descartes, Private practice, Paris \\ ${ }^{3}$ DDS MCU-Ph.D., Paris Descartes, Private Practice, Paris \\ ${ }^{4}$ DDS MCU-Ph.D. Director of the Biomaterials Laboratory Urb2i, Unit, EA4462, Private practice, Paris
}

\begin{abstract}
Enamel spots are frequently reported as an aesthetic complaint. In the case of orthodontic treatment, these spots can be a cause for concern, on one hand, for the orthodontist: what is the origin of these spots? Is it possible to bond directly on these areas without any risk? How and when should they be treated? On the other hand, from the patient's point of view, the appearance or persistence of these spots can decrease the esthetic benefits of treatment.

The aim of this article is to describe the diagnosis, treatments, and management guidelines (protocols and chronology); present the benefits of the minimally invasive approach; and propose systematic guidelines for orthodontists.
\end{abstract}

\section{INTRODUCTION}

Opacities of the enamel (white, yellow, or brown spots) are an increasingly frequent reason for an esthetic consultation. If these opacities are not systematically treated, they may appear more problematic before and after orthodontic treatments:

- Before treatment, orthodontists are sometimes poorly informed. Can I attach anything to this damaged enamel? Is there a need for prior treatment? If yes, what treatment type? What will happen upon removal?

- After treatment, patients and practitioners can be surprised by the "appearance" of enamel spots. Were they present beforehand? Were they aggravated or caused by the treatment? Could they have been avoided? Is it possible to make them disappear?

The purpose of this article is

Address for correspondence:

Anthony Atlan - 37 rue des Acacias - 75017 Paris

E-mail: dr.atlan.anthony@gmail.com

Article received: 18-02-2017. Accepted for publication: 29-02-2017.

This is an Open Access article distributed under the terms of the Creative Commons Attribution License (http://creativecommons.org/licenses/by/4.0), which permits unrestricted use, distribution, and reproduction in any medium, provided the original work is properly cited. 
- to describe a simple approach to set the correct diagnosis;

- to analyze, according to the literature, the impact of preventive techniques on the appearance and/or development of enamel spots;
- to show the benefits of minimally invasive techniques for the treatment of these spots within the framework of orthodontic care;

- to propose a care procedure before.

\section{DESCRIPTION AND ETIOLOGY14}

White enamel spots, also called opacities, are always related to hypomineralization, which is a decrease in the local concentration of minerals.

This decrease may be because of

- a loss of minerals. This is the case with early-stage carious lesions. During the carious process, bacteria produce acids, which dissolve minerals;
- a lack of minerals being incorporated during amelogenesis, which occurs in some pathologies during the mineralization phase: fluorosis, permanent tooth trauma, and molar incisor hypomineralization (MIH).

It is therefore possible to distinguish between two types of lesions:

- pre-eruptive lesions, which are caused by a disturbance of the

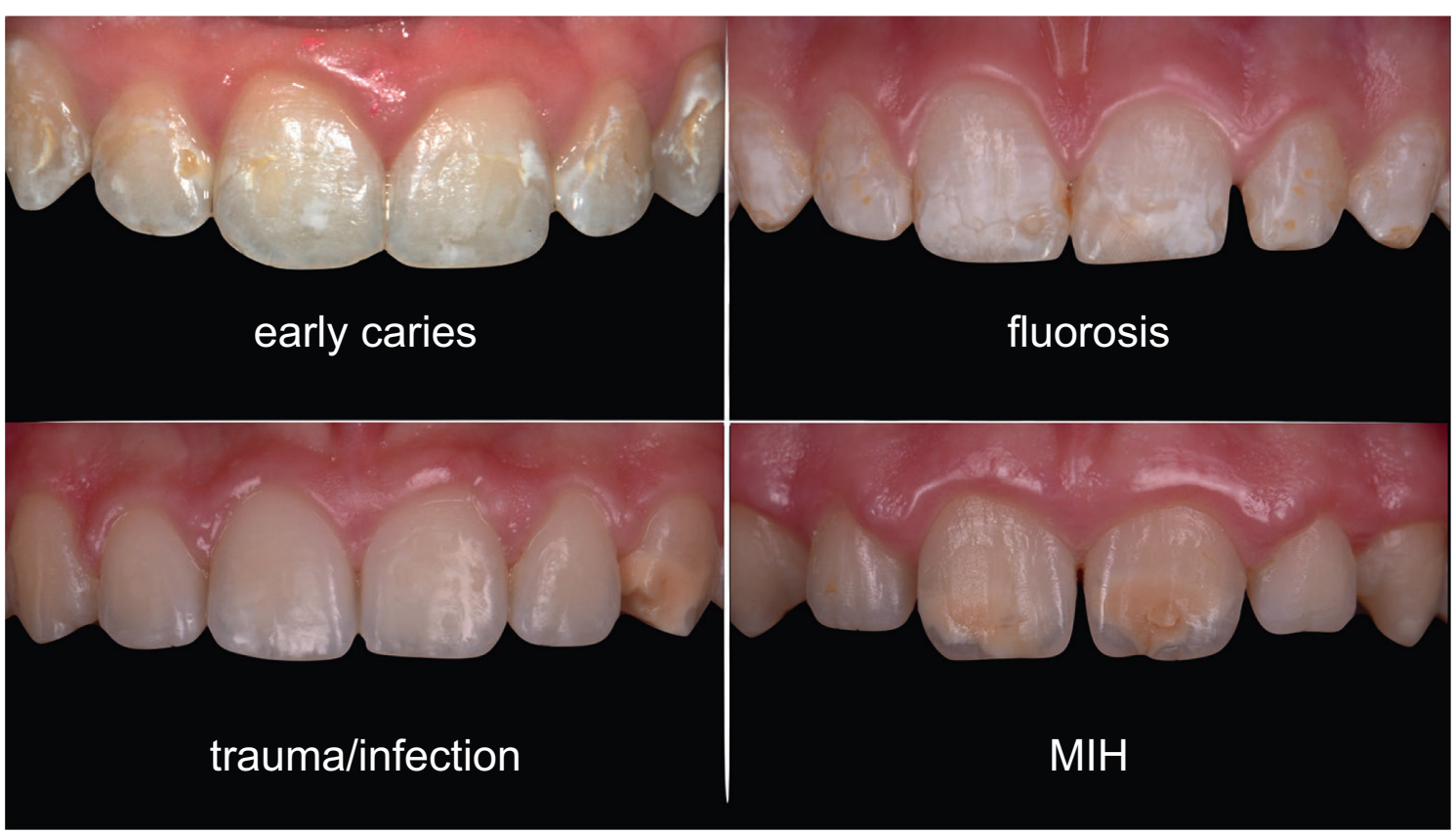

Figure 1

Pathologies that may cause enamel spots are carious diseases; fluorosis, trauma and infections of temporary teeth, and molar incisor hypomineralization (MIH). 
amelogenesis process. These lesions are visible as soon as the tooth erupts on the arch;

- posteruptive lesions, which are exclusively linked to the carious process and are thus systematically classified as early-stage carious lesions.

The time of occurrence of these lesions occur in relation to the orthodontic treatment facilitates their diagnosis: The total absence of a lesion before treatment will point to a diagnosis of enamel carious lesions of the enamel (formerly called precarious leucomas).

In the end, there are only four possible diagnoses (Fig. 1) for an almost total opacity of the enamel.

\section{Carious lesions of the enamel (white spots/precarious leucomas;} Fig. 2)

Pre-carious leucomas correspond to the 1st clinically visible stage of the carious process. They therefore have to appear around the plaque accumulation

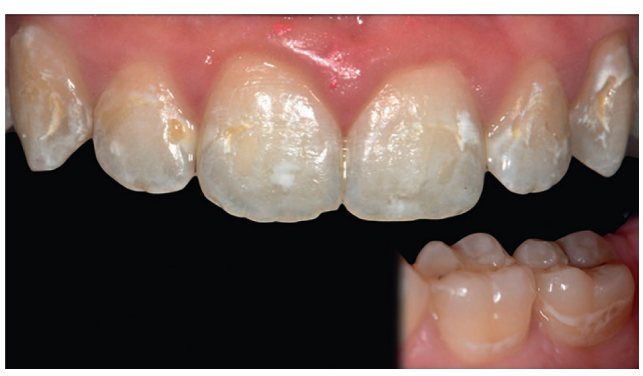

Figure 2

Patients with enamel cavities because of a lack of hygiene during a multiattachment treatment. These lesions are characterized by the following: always located around the plaque accumulation zone; circular in shape when anterior, semicircular in shape when posterior; chalky white/yellow/brown appearance; may be associated with a loss of enamel. zone. The most common locations and forms are

- circular, vestibular to the anterior teeth. This localization is specifically linked to multiattachment treatments;

- semicircular, at the cervical level of the posterior mandibular teeth.

The enamel appears matte white, rough on the surface, but without any enamel cavities.

At the tissue level, the lesion starts on the surface and develops toward the dentin.

\section{Fluorosis (Fig. 3)}

Fluorosis is a hypomineralization of the enamel associated with fluoride poisoning during amelogenesis.

It is a systemic poisoning. As a result, fluorosis-related lesions are always symmetrical on homologous teeth and often found on several groups of teeth. They may appear white, yellow, or brown, depending on the degree of hypomineralization. They can be accompanied by horizontal striations.

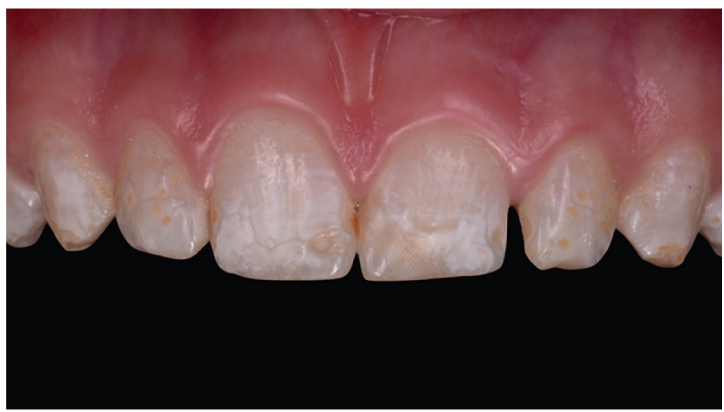

Figure 3

Patient with fluorosis. The lesions present the following characteristics: symmetrical; widespread; cloudy/milky; sometimes associated with horizontal streaks. 


\section{Trauma/infection of temporary teeth (Fig. 4)}

Any disturbance to the roots during amelogenesis may result in a hypomineralization lesion. This disturbance can be mechanical, such as temporary tooth trauma or infections.

The lesions associated with it can take any shape, location, or shade. They are related to the age when the trauma occurred. They are most often punctiform, located on the incisors, and are most often limited to one or two teeth. The contralateral teeth are not affected; however, there may be antagonistic tooth damage in the case of chin trauma with pressure on the temporary antagonistic teeth.

However, the most benign trauma is likely the cause of such a lesion. It is therefore common for parents or patients to not be able to remember how the trauma occurred. This aspect should not eliminate this diagnosis, which is most often a diagnosis of exclusion.

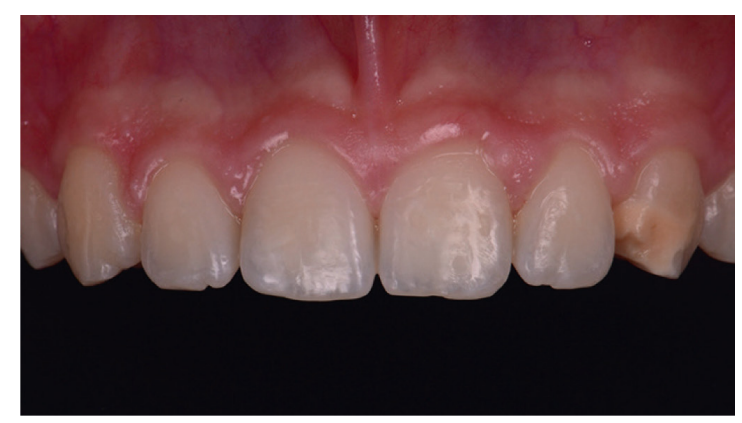

Figure 4

Patient with a unique lesion on 23. No other teeth are affected. This lesion may be related

to a traumatic injury or infection of the temporary tooth during the amelogenesis of the underlying root. Antagonistic lesions are searched for but were absent. Diagnosis of traumatic injury is made by exclusion of differential diagnoses.

\section{MIH (Fig. 5)}

$\mathrm{MIH}$ is a pathological entity whose etiology remains unknown. It is defined as the presence of at least one hypomineralization lesion on a permanent first molar, whether or not it is associated with lesions on the incisors. It usually affects the canines and the second molars.

Clinically, in painless forms, the clinical course is reversed: Patients consult for spots on the incisors and it is up to the practitioner to inspect the first molars for making this diagnosis.

These lesions appear as well-defined opacities of white, yellow, or brown color involving the incisors.

The presence of restorations on the first molars or the absence of these teeth in the mouth of a person deemed to be at a low risk of developing carious lesions can point toward the diagnosis of $\mathrm{MIH}$.

In the case of $\mathrm{MIH}$, the lesion always starts from the junction between the enamel and the dentin. Regardless of whether it affects all or part of the enamel layer, it is always deep.

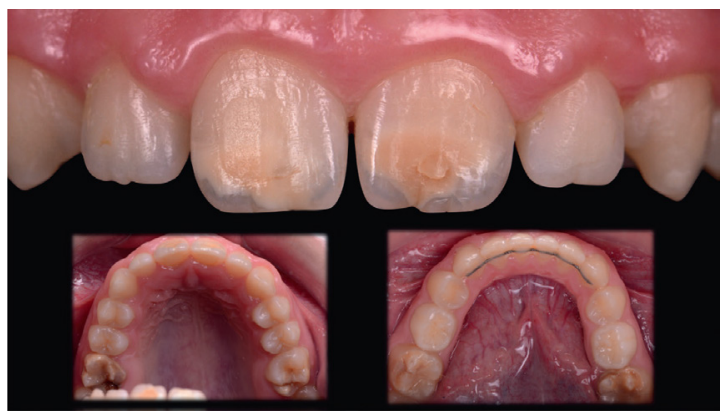

Figure 5

Young patient with lesions of molar incisor hypomineralization (MIH) on 11 and 21. These lesions are systematically associated with lesions on the first permanent molars (visible on occlusal views); they are generally located on the incisors, are white, yellow, or brown in color; and are deep. 


\section{ENAMEL SPOTS AND ORTHODONTIC TREATMENT}

\section{Are orthodontic treatments the cause of such lesions?}

Only early-stage carious lesions may be related to orthodontic treatment.

The prevalence of early-stage carious lesions is twice as high in patients receiving orthodontic treatment $49 \%$ vs. $24 \%)^{17}$.

In $75 \%$ patients, these lesions affect more than two teeth.

The age of the patient seems to be the most predictive factor ${ }^{21}$ : these lesions are found in $52 \%$ patients who received orthodontic treatment between the ages of 11 and 15 years, compared with 7\% for patients who have been treated orthodontically between the ages of 19 and 24 years.

The retention of bacterial plaque related to the use of orthodontic equipment appears to be the basis of this problem. Thus, prevention is the best approach.

Classically, it is built around three axes:

Hygiene: This is the critical point when wearing orthodontic braces. A specific toothbrush is insufficient. Additional measures must be put in place. Interdental brushes and flosses must be used daily;

Diet: Limitation of the frequency of intake of sugar;

Fluorination (toothpaste $>1,500$ ppm)/ remineralization (combination of casein phosphopeptide and amorphous calcium phosphate, Recaldent ${ }^{\circledR}$ ): professional and outpatient, in the form of toothpaste and mouthwash.

It is evident from the perspective of the practitioner that the lack of compliance with hygiene is the cause and not the orthodontic treatment itself.
However, a study shows two interesting facts:

- There is indeed a relationship between the compliance of patients in relation to the prophylactic techniques and the development of early-stage carious lesions, but this relationship is not strong enough to be statistically significant in a sample of 80 patients ${ }^{18}$.

- Patients with the best compliance still present with new lesions after orthodontic treatment.

In conclusion, the establishment of a strong prophylaxis is mandatory, and the compliance of the patients must be regularly evaluated. A strong compliance does not fully prevent the onset of early-stage carious lesions.

\section{How to decrease the risk of appearance? (Clinical case \# 1: Figs. 6-8)}

From an etiological point of view, it is therefore not possible to say that orthodontic treatment causes lesions. On the other hand, the likelihood of the onset of these lesions following orthodontic treatment is very high and no prophylactic techniques can completely prevent it.

Patients should be warned of this risk.

In response to this problem, proposals for attaching orthodontic devices using bioactive materials, such as glass ionomer cement have been described. The results of the evaluations seem largely in favor of GIC compared to composite resins with regard to the 


\section{Clinical case 1}

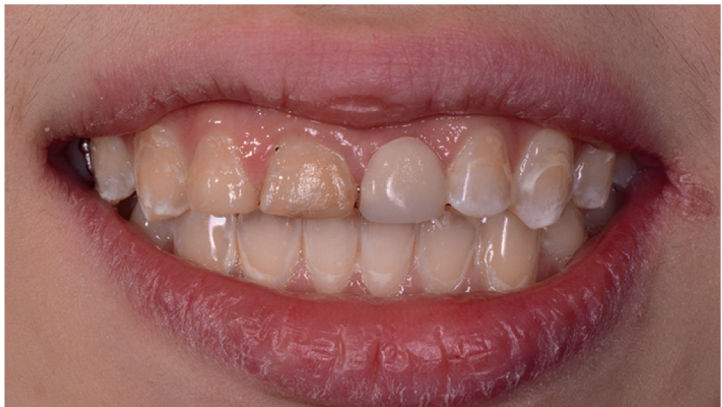

Figure 6

Clinical case no. 1 (Figs. 6-13): Patient at the end of orthodontic treatment, wearing a removable device on 21, sought an esthetic consultation related to the discoloration on 11 and to the white spots that appeared during the treatment. She wanted to have a more esthetic fixed prosthesis to replace 21.

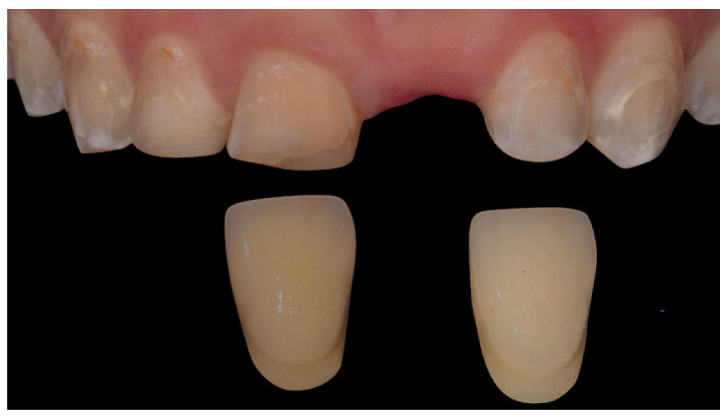

Figure 8

Intraoral view in polarized light: Dyschromia of 11 , as well as the general saturation of the teeth indicate, a prior lightening treatment.

Risk factor management, oral hygiene education, and outpatient fluoridation are implemented. Note: Photos in polarized light allow the dental structures to be observed without reflections. The shade and trans/ucidity of the different structures can be better evaluated. They are made using specialized filters (Polar eyes ${ }^{\circledR}$ ).

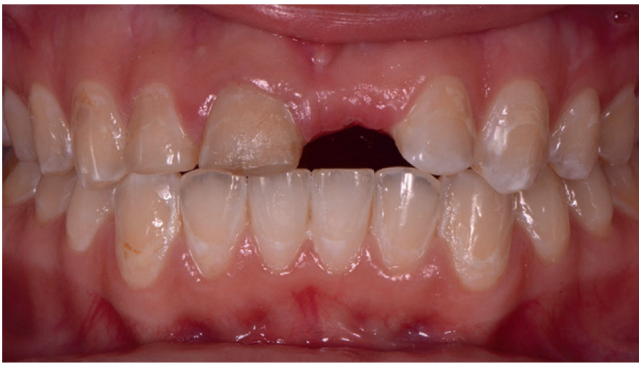

Figure 7

Intraoral view: The circular and semicircular shape of the lesions and the onset of the lesions points to a diagnosis of carious lesions of the enamel.

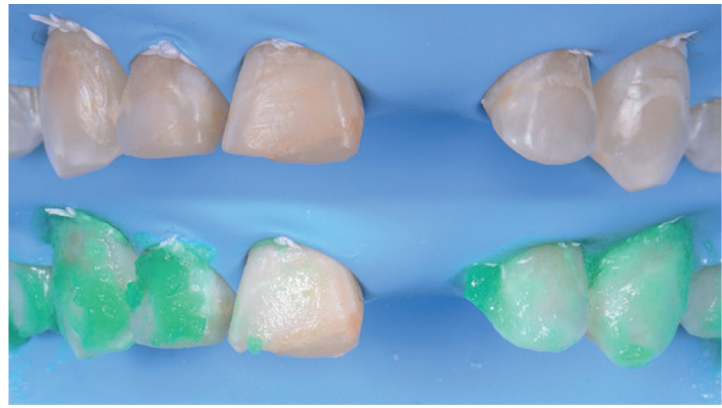

Figure 9

Intraoperative maxillary intraoral views (montage): 2 weeks after the end of the lightening treatment, the surgical field type latex gutter is set, and ligatures are created so that they reach the most cervical areas. The hydrochloric acid gel (Icon Etch $\left.{ }^{\circledast}, D M G\right)$ is applied for 2 min.

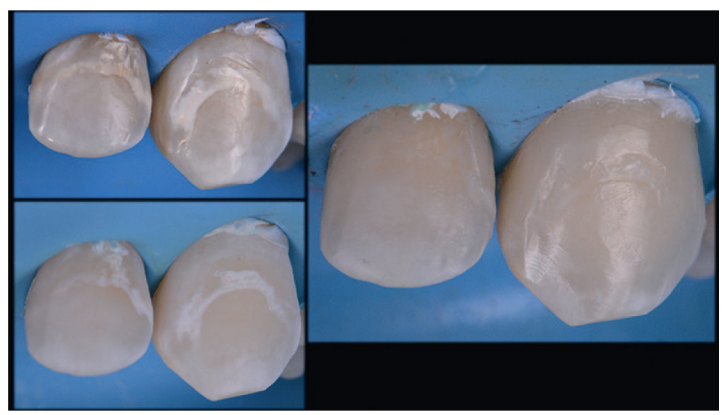

Figure 10

Intraoperative views of 22 and 23: before treatment (upper left); after acid treatment and dehydration (lower left); after infiltration (right). 


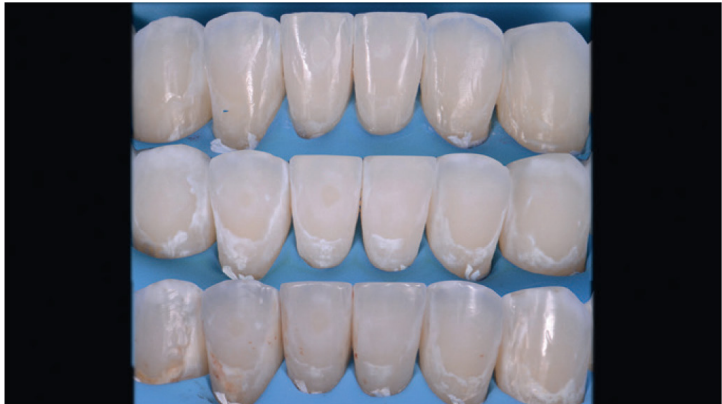

Figure 11

Montage of three intraoperative clinical views from 33 to 43. From bottom to top: before treatment; after acid treatment and dehydration; after infiltration.

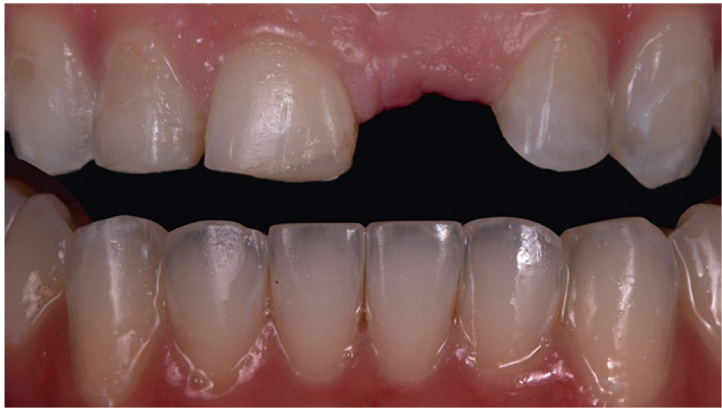

Figure 13

Postoperative intraoral view in diffuse light (montage): At this stage, individual carious risk has been drastically decreased. The lesions have been treated. The prosthetic support can be initiated.

appearance of these postorthodontic white spots ${ }^{41,11,9,24,36}$. These studies also report similar adhesion values between composites and GIC, particularly in the case of a previous etching treatment using orthophosphoric acid. However, GIC is not often used. Ergonomics and habits seem to be important barriers. Although it is easily understandable to prefer the use of composite resins in the case of direct attachment techniques, it could be very interesting to use indirect techniques for which the use of GIC is so simple, especially in

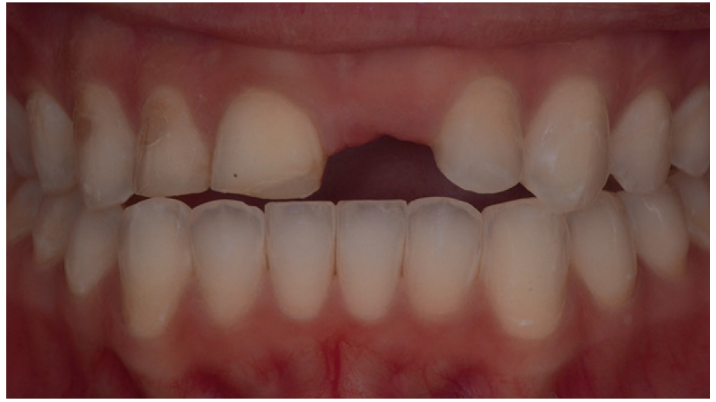

Figure 12

Postoperative intraoral view in polarized light: an overall improvement of the teeth can be observed. The dyschromia is no longer detectable on 11. White spots are no longer visible.

cases of young patients, or in patients with poor hygiene and compliance.

Other proposals have been published, including the use of the following:

- protective coatings;

- elastomeric ligatures containing tin fluorides;

- antimicrobials (iodine, chlorhexidine, cetylpiridimine chloride);

- antibacterial nanoparticles coated on orthodontic attachments (titanium dioxide, zinc oxide);

- new processes for the manufacture of ceramics by freezing (freeze casting) allowing the incorporation of antimicrobial polymers.

These proposals have not yet shown merit, or are still being evaluated.

\section{Associated mechanical risks}

Hypomineralization lesions can cause esthetic problems, but it can also make the enamel more fragile, especially when the lesion is located on the surface (clinical case no. 2, Figs. 14 and 15). This aspect is particularly problematic when attaching the orthodontic devices. 
Pretreatment of the injured enamel is then recommended before orthodontic treatment. (see the $\S$ following "infiltration")

\section{HOW TO TREAT THESE LESIONS?}

\section{Remineralization}

Because these lesions correspond to a decrease in the mineral concentration, the ideal treatment is their remineralization?. Unfortunately, remineralization treatments are exclusively indicated for eruptive lesions, when the mineral loss occurred after the eruption of the tooth, i.e., in the case of early-stage carious lesions.

On the other hand, their effectiveness is limited to the most superficial of lesions.

ICDAS (International Caries Detection and Assessment System) Stage-1 lesions (see table) disappear completely after remineralization treatment. However, these lesions do not create cosmetic problems for patients.

In the case of ICDAS Stage-2 lesions, the remineralization treatments result in a reduction of up to half the size of the lesion ${ }^{40}$. On the other hand, after 3 months of treatment, there is no more improvement ${ }^{30}$ An alternative treatment should be considered.

There are currently no clinically evaluated protocols that have demonstrated superiority. The results of the different studies cannot be compared because of the diversity of protocols used, including the use of various chemicals, duration of treatment, application modality, and compliance monitoring.

On the other hand, all studies conclude a beneficial effect in terms of decreasing the risk of caries by stopping the process in esthetic and mechanical terms at the enamel tissue level.

ICDAS is a system for classifying carious lesions ${ }^{20}$. It allows a reliable comparison and an association between

\begin{tabular}{|l|l|l|}
\hline Score & Clinical criteria & Histology \\
\hline 0 & $\begin{array}{l}\text { Absence or slight change in the translucen- } \\
\text { cy of the enamel after prolonged drying }\end{array}$ & No free demineralization \\
\hline 1 & $\begin{array}{l}\text { Opacity or staining not easily visible on } \\
\text { a moist surface, but visibly distinguished } \\
\text { after drying. }\end{array}$ & $\begin{array}{l}\text { Demineralization limited to half of external } \\
\text { enamel }\end{array}$ \\
\hline 2 & $\begin{array}{l}\text { Clearly visible opacity or staining } \\
\text { Presence of an enamel cavity at the level } \\
\text { of a stained opaque enamel and/or grayish } \\
\text { discoloration of the underlying dentine }\end{array}$ & $\begin{array}{l}\text { Demineralization reaching the inner third } \\
\text { of thenamel, dentin can be affected }\end{array}$ \\
\hline 4 & $\begin{array}{l}\text { Cavity within opaque or stained enamel } \\
\text { with dentin exposure }\end{array}$ & $\begin{array}{l}\text { The entire thickness of the enamel is } \\
\text { reached, the dentine is infected. }\end{array}$ \\
\hline
\end{tabular}


the clinical aspect of the lesion and the histological characteristics.

Note: Studies report remineralization protocols for eruptive lesions. The results look promising, but the available studies do not yet allow for widespread use $^{25,12}$

\section{Bleading}

Even if dental lightening treatment does not deal with the hypomineralization problem in any way, its use can be very interesting for two reasons:

- At the esthetic level, the perception of these lesions can be accentuated by the contrast between the stain and the surrounding healthy enamel. Thus, the lightening helps to decrease this contrast and the visual perception of the spots;

- These hypomineralization lesions do not always appear white. They can be discolored and appear yellow or brown. Histologically, this results in the presence of molecules or chromophores within the porous structure of the hypomineralized enamel. The esthetic problem is then twofold: There is the opacity and the discoloration. Lightening is, therefore, used to extract the chromophores from the lesion to make it white.

The infiltration treatment will then restore the hypomineralized opaque enamel to its translucent appearance.

Superficial treatments using thermoformed gutters and 10\% carbamide peroxide gels for 3 weeks demonstrated long-term effectiveness and safety.

They have shown a clinical effect for nearly 30 years ${ }^{19,26,42,22}$.

\section{Infiltration}

The idea of treating white spots with resin infiltration was first developed by Davila and Buonocore in $1975^{13}$ as part of the early treatment of enamel caries, but it was not successful. It was not until the 2000s that Meyer-Lueckel and Paris $27,31,32,33,28$ improved the protocols and the performance of the materials and develop a system dedicated to this new type of treatment called infiltration.

The idea of treating enamel cavities with resin infiltration is based on the following reasoning:

- the white spots caused by the carious process are areas of hypomineralized enamel and are therefore present porosities;

- the infiltration of these porosities with a polymerizable resin blocks the diffusion of bacterial acids and the passage of nutrients and stops the carious process.

Before being able to infiltrate these porosities, it is necessary to make the surface enamel layer permeable, which is most often hypermineralized. This permeabilization is carried out using a 15\% concentrated hydrochloric acid gel during a preliminary erosion stage.

Today, a single system is currently available commercially for this indication: it is the Icon (DMG) System ${ }^{\circledR}$.

Beyond the biological uses, these techniques are accompanied by two additional desirable effects:

- the resin infiltration mechanically reinforces the hypomineralized enam$\mathrm{el}^{2,8,23,38}$ which is particularly interesting in orthodontic management 


\section{Clinical case \#2}

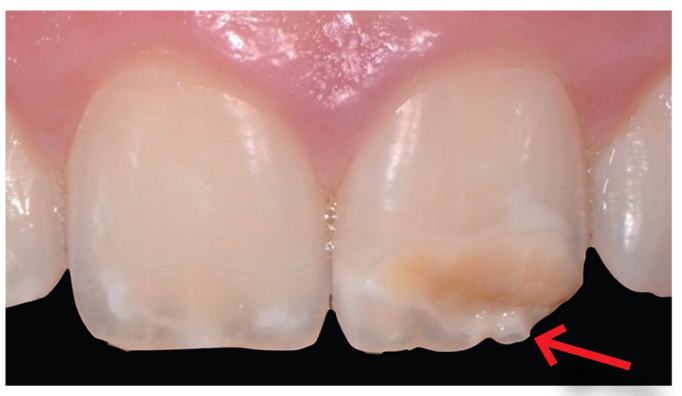

Figure 14

Clinical Case \# 2 (Figs. 14-21). A young patient (age 8 years) consults for an esthetic complaint related to a brown spot on 21. White spots are detected on 11. The first molars, which are in the process of erupting, also show brown lesions. MIH is given as a diagnosis. On the day of the first consultation, a loss of substance at the distal angle of 21 is visible. A small, healthy enamel spur persists (red arrow). The orthodontic consultation indicates early treatment. The indication of deep infiltration before orthodontist treatment is posed.

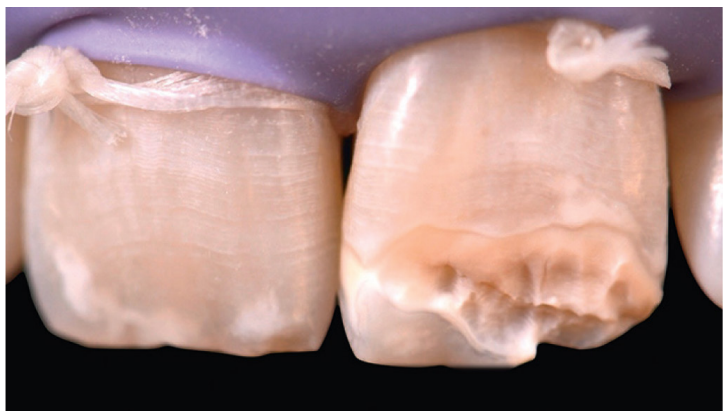

Figure 16

The operative field is placed. Outer layers are removed using a micro-sandblaster (RONDOflex $\left.{ }^{\Theta}, \mathrm{KaV} O\right)$. The idea is not to eliminate the entire lesion, but to reach the deepest porosities.

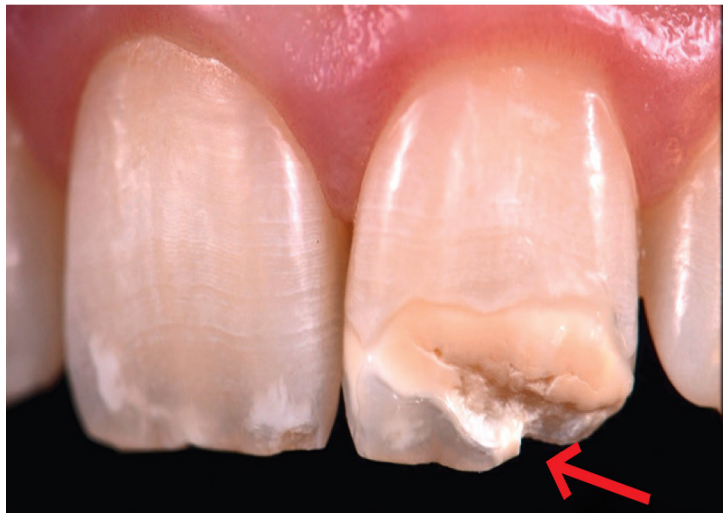

Figure 15

Consultation on the day of the infiltration treatment. Over a few weeks, mastication induced an additional, asymptomatic, loss of substance. The healthy enamel spur has been lost. The stain has a brown coloration. The age and incomplete eruption of the posterior permanent teeth do not allow for lightening.

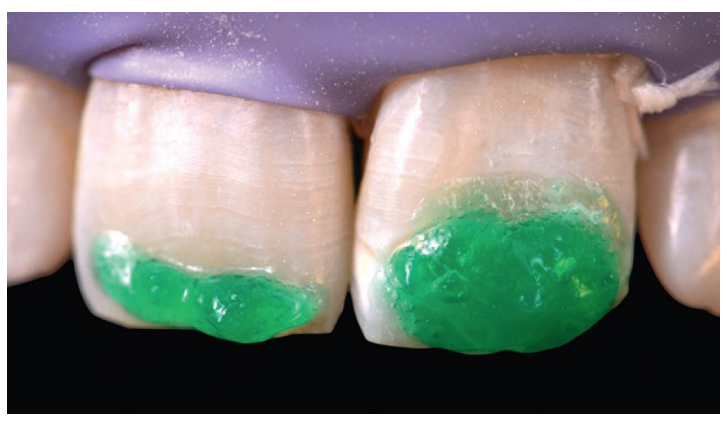

Figure 17

Application of hydrochloric acid gel (Icon Etch $\left.^{\circledast}, D M G\right)$. 


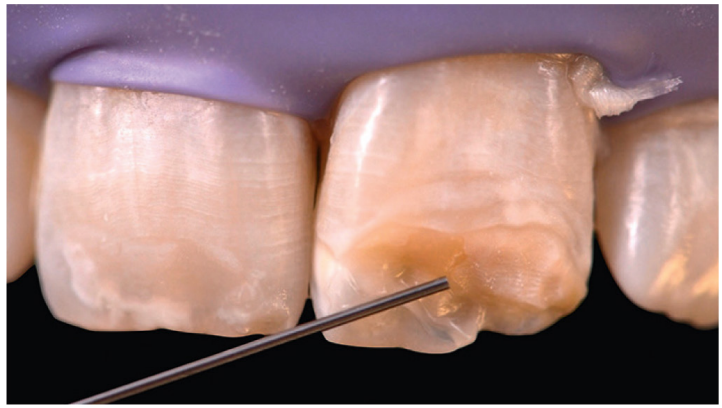

Figure 18

The application of the ethanol solution (Icon Dry $\left.{ }^{\circledR}, D M G\right)$ after rinsing.

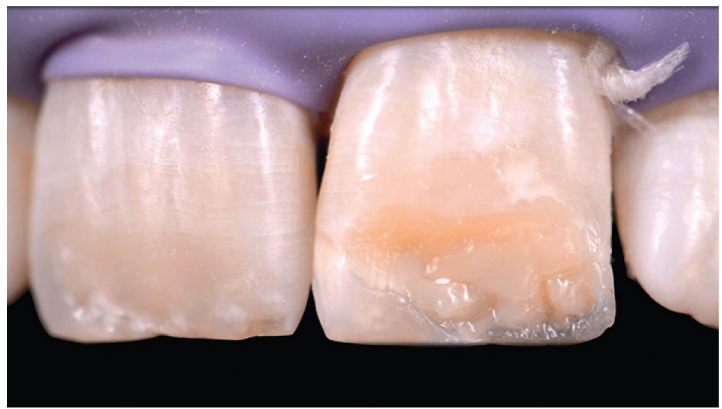

Figure 20

A composite stratification technique (Empress Direct ${ }^{\circledR}$, Ivoclar) is used to restore the distal angle.

(clinical case no. 2 Figs. 14-21, and clinical case no. 3, Figs. 22-39);

- the infiltration is accompanied by disappearance of the spots ${ }^{35}$. It gives the hypomineralized enamel a translucent aspect ${ }^{3}$.

Although these techniques have been developed for the treatment of early stage carious enamel lesions, the esthetic results have prompted clinicians and researchers to broaden the scope of the indications. Because all enamel spots have porosities, it has been possible to describe specific protocols depending on the type of stain and the

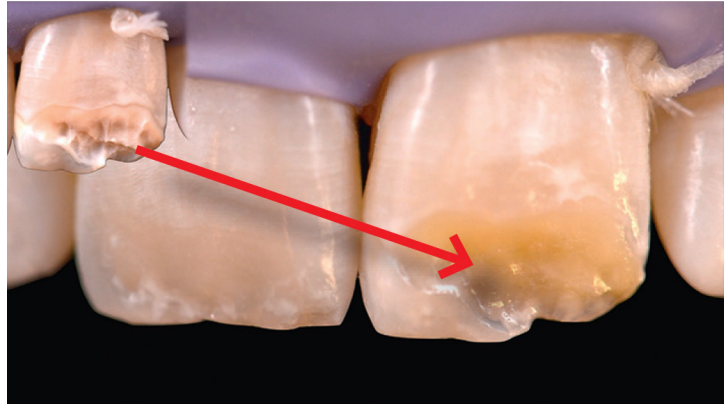

Figure 19

View after infiltration. The stain still has a yellowish-brown appearance, but the enamel has regained its translucent appearance, evidence of deep infiltration of the porosities.

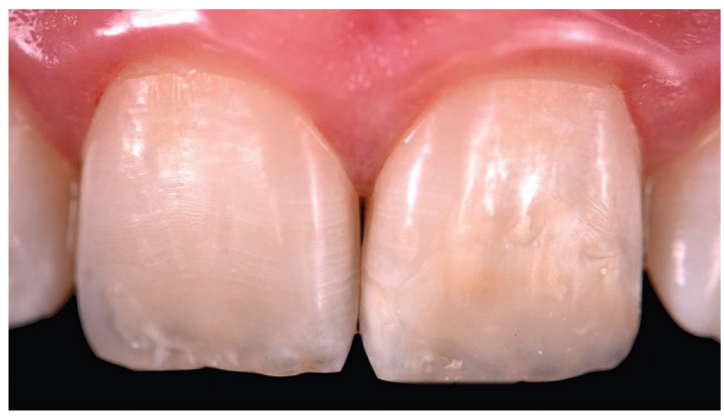

Figure 21

Postoperative view. Polishing and brightening have not been finished. An orthodontic brace will soon be applied in this location. It can be safely attached.

diagnosis $16,6,37,5,15,4$, There are now two infiltration protocols ${ }^{6,3}$

- a simple infiltration protocol, with an exclusive chemical treatment, without the addition of a composite. This technique is reserved for lesions near the enamel surface (clinical case no. 1);

- a deep infiltration protocol, which combines a mechanical and chemical treatment, and which requires the filling of an induced cavity, with a composite contribution, in a single shade without stratification (clinical case 3, Fig. 22-39). 
Clinical case \#3

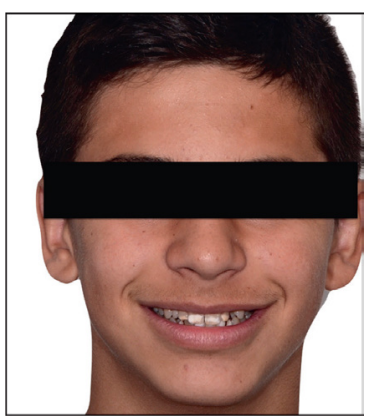

Figure 22

Clinical case no. 3 (Fig. 22-39).

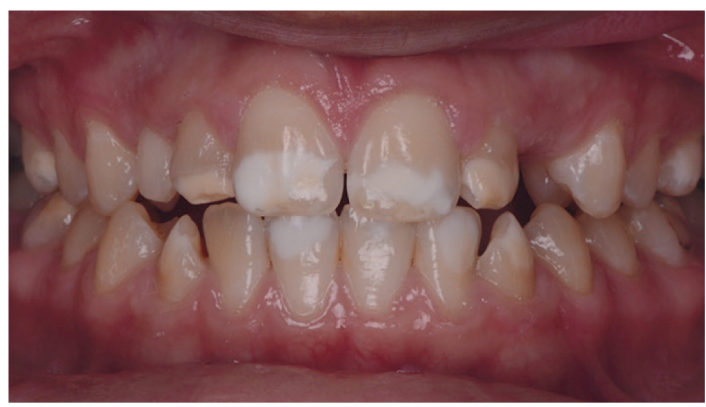

Figure 24

Loss of substance is associated with these lesions, particularly on the lateral side. Lesions are found on the 1st permanent molars. MIH is provided as a diagnosis.

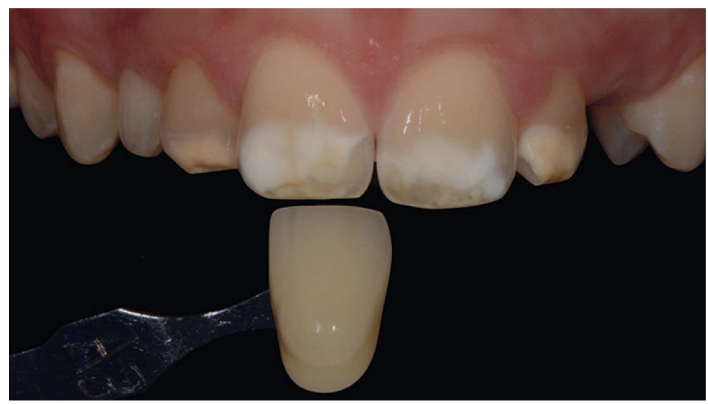

Figure 26

Polarized light view before lightening treatment.

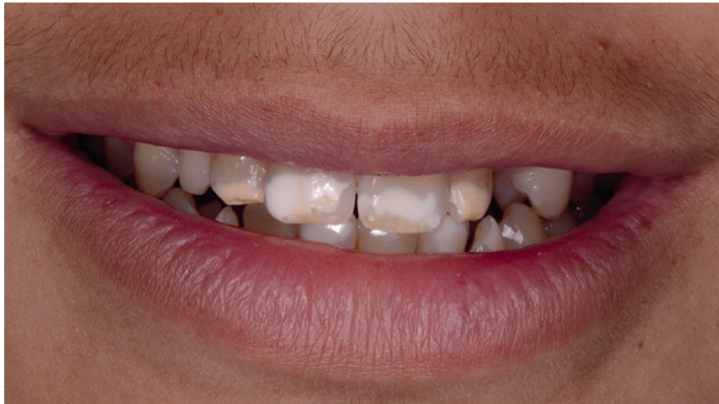

Figure 23

Patient referred by their orthodontist. The patient (age 14 years) complains of a severe esthetic problem. His father accompanied him and has witnessed the beginning of discoloration. Orthodontic treatment is indicated but the practitioner is reluctant to attach the fasteners to these spots.

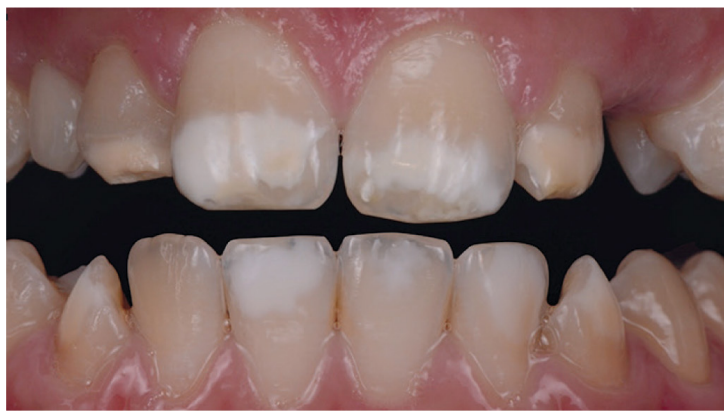

Figure 25

$\mathrm{MIH}$-related lesions always begin at the junction between the enamel and dentin. In this case, they have reached the surface and therefore have affected the whole enamel. Given the need for orthodontic treatment and the fragility of the enamel at the level of these lesions, a lightening treatment and a deep infiltration treatment are indicated before orthodontic treatment. 


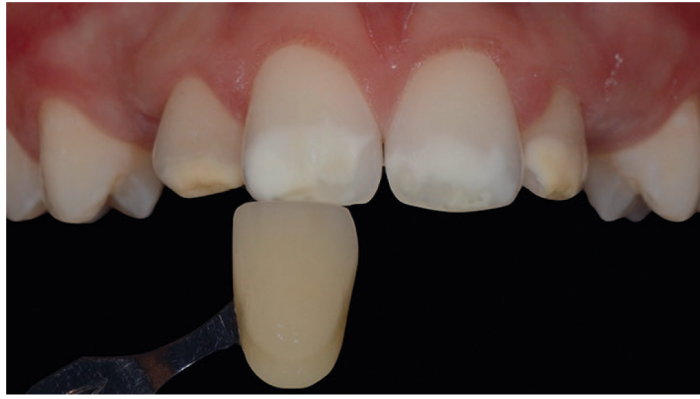

Figure 27

Polarized light view after lightening treatment. This treatment has two effects: a decrease in the contrast between the general shade of the teeth and the spots as well as a decrease in discoloration within the spots.

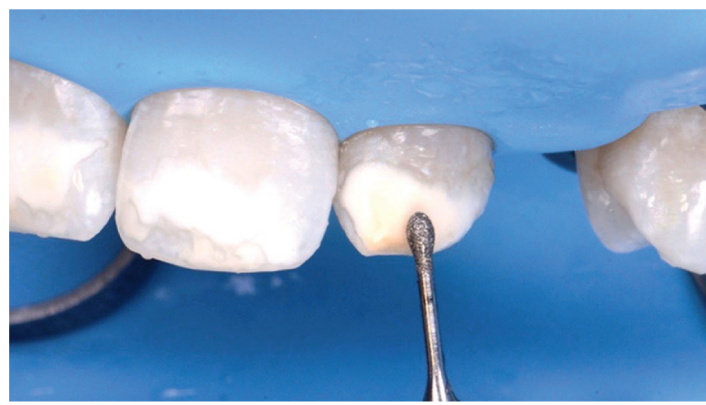

Figure 29

Unlike conventional infiltration treatment, during a deep infiltration, a mechanical treatment is used from the outset to reach the deepest porosities of the enamel layer.

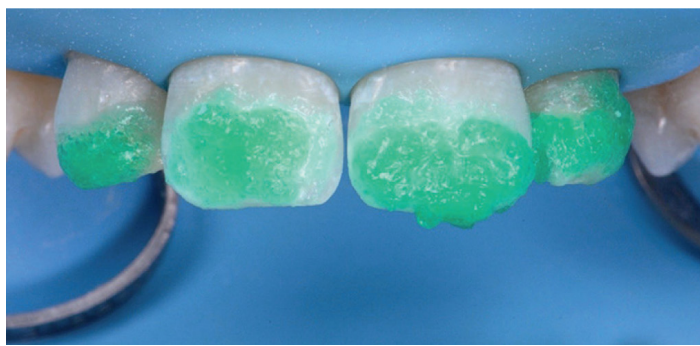

Figure 31

Application of the hydrochloric acid gel IIcon Etch $^{\circledR}$.

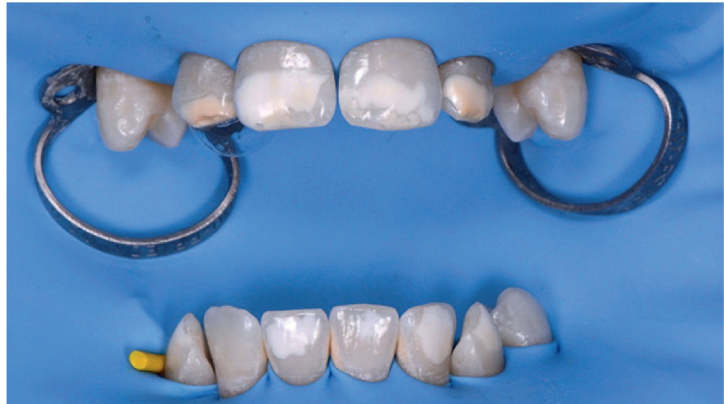

Figure 28

Two weeks after the end of the lightening treatment, the operative field is placed simultaneously in the maxilla and mandible.

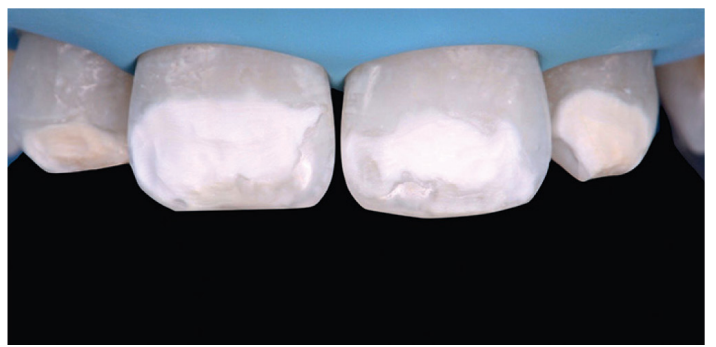

Figure 30

View after mechanical removal of surface layers.

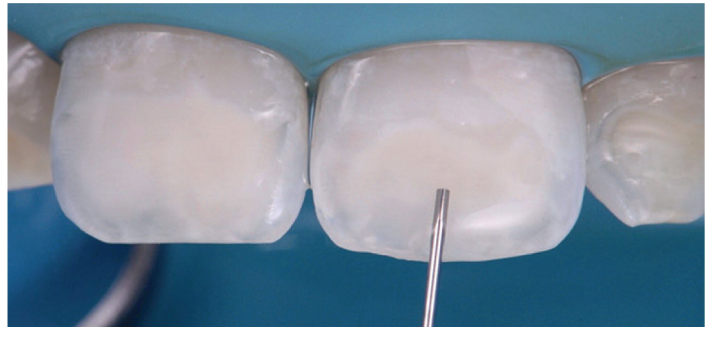

Figure 32

An ethanol solution (Icon Dry ${ }^{\circledR}$ ) is applied after rinsing. This step makes it possible to dehydrate the periosteal areas to prepare for infiltration with a hydrophobic resin, which provided intraoperative stimulation. 


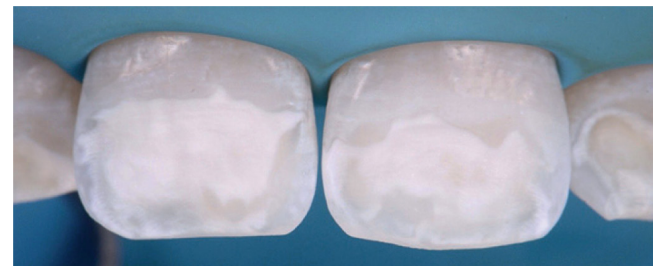

Figure 33

After dehydration, the white spots are clearly visible. This ensures the absence of dentinal involvement and effective dehydration.

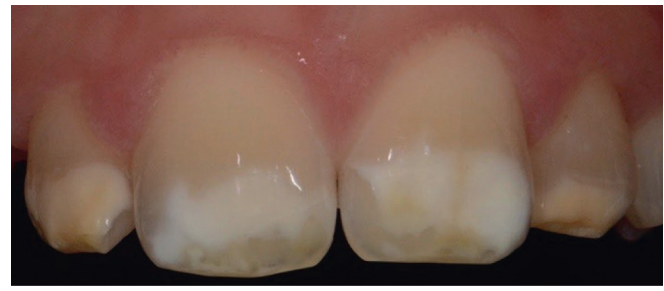

Figure 35

Polarized light view of 12 to 22 before treatment.

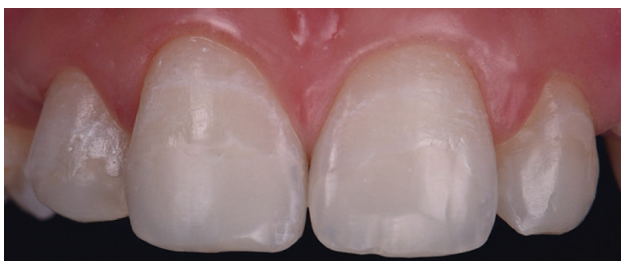

Figure 37

View of 12 to 22. The composites are just polished, without any particular surface finish, because an orthodontic attachment will be quickly put in place.

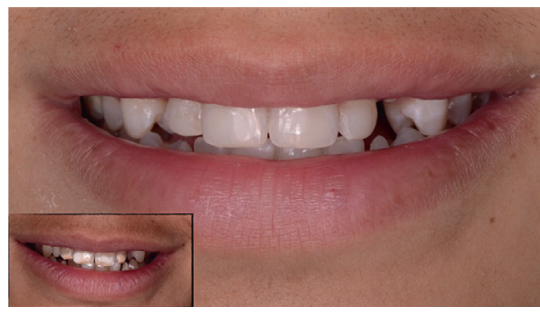

Figure 38

View of the smile from before (framed) and after treatment. The esthetic problem presented by the spots is solved. The enamel is protected. Orthodontic devices can now easily be attached without any risk of causing aggravation.

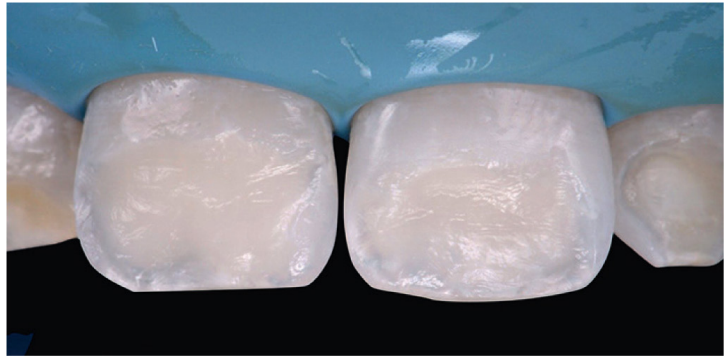

Figure 34

View after infiltration. Spots are no longer visible. The concavity created by the mechanical and chemical elimination of the superficial enamel layers is then filled by a single contribution of enamel-colored composite (Universal Enamel 2 Enamel HRi巴, Micerium) without stratification.

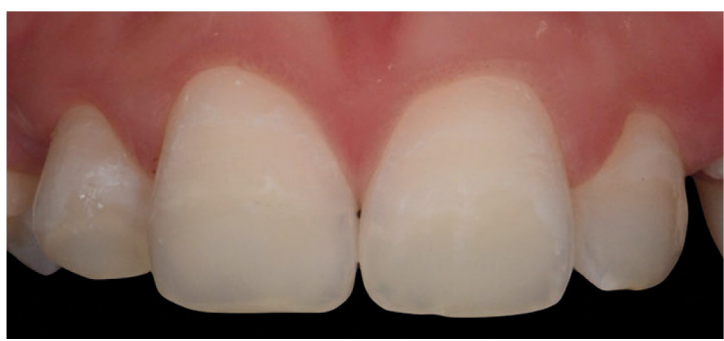

Figure 36

Polarized light view of 12-22 after treatment.
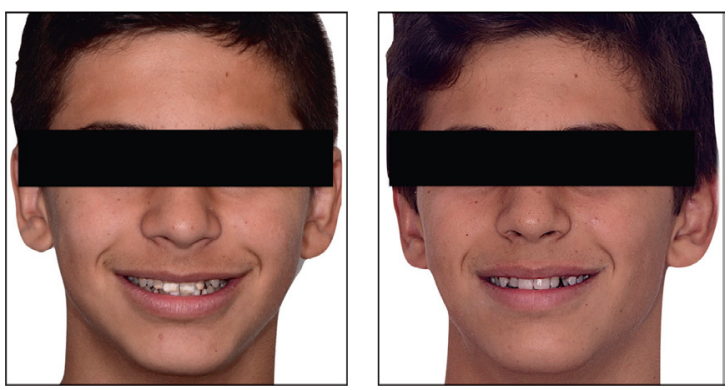

Figure 39

View of the smile before and after treatment. 
Clinical case \#4

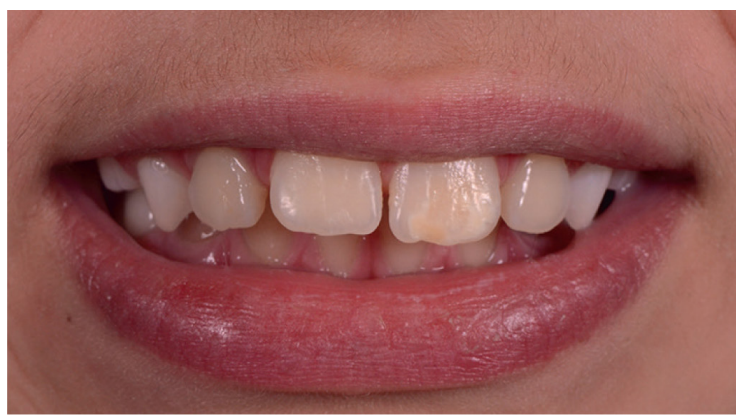

Figure 40

8-year-old patient, referred by an orthodontist. Early orthodontic treatment is planned. The patient and her mother reported a relative esthetic complaint.

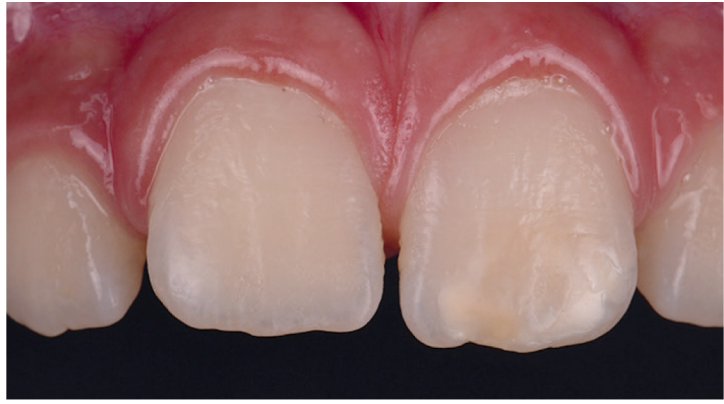

Figure 41

MIH was diagnosed. The enamel surface appears to be undamaged with no associated loss of substance. An orthodontic device can be attached with a low risk of deterioration. The separation during removal will preferably be within the bonding composite.

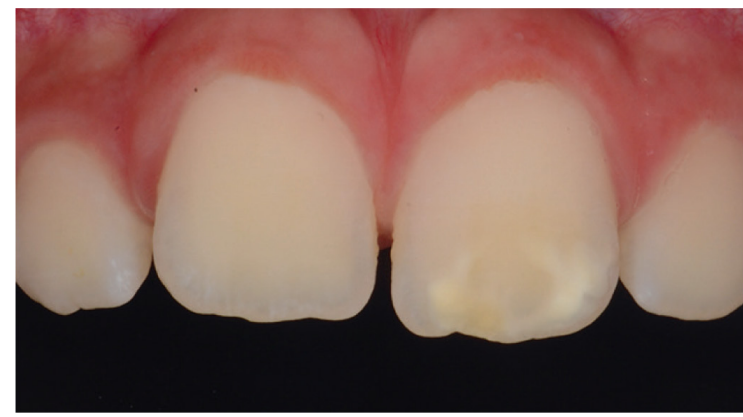

Figure 42

Polarized light view.

\section{GUIDELINES FOR THE ORTHODONTIST}

Two situations must be distinguished.

\section{Spots are present before treatment (Decision Tree Fig. 43)}

The indication of an orthodontic treatment is suggested but spots are visible (clinical cases no. 2, 3, and 4).
In the case of early-stage carious lesions, the priority is to stop the carious process, through the management of risk factors, the control of the general practitioner, the setting up of outpatient and professional fluoridation, and the treatment of active dentin lesions, if necessary. 


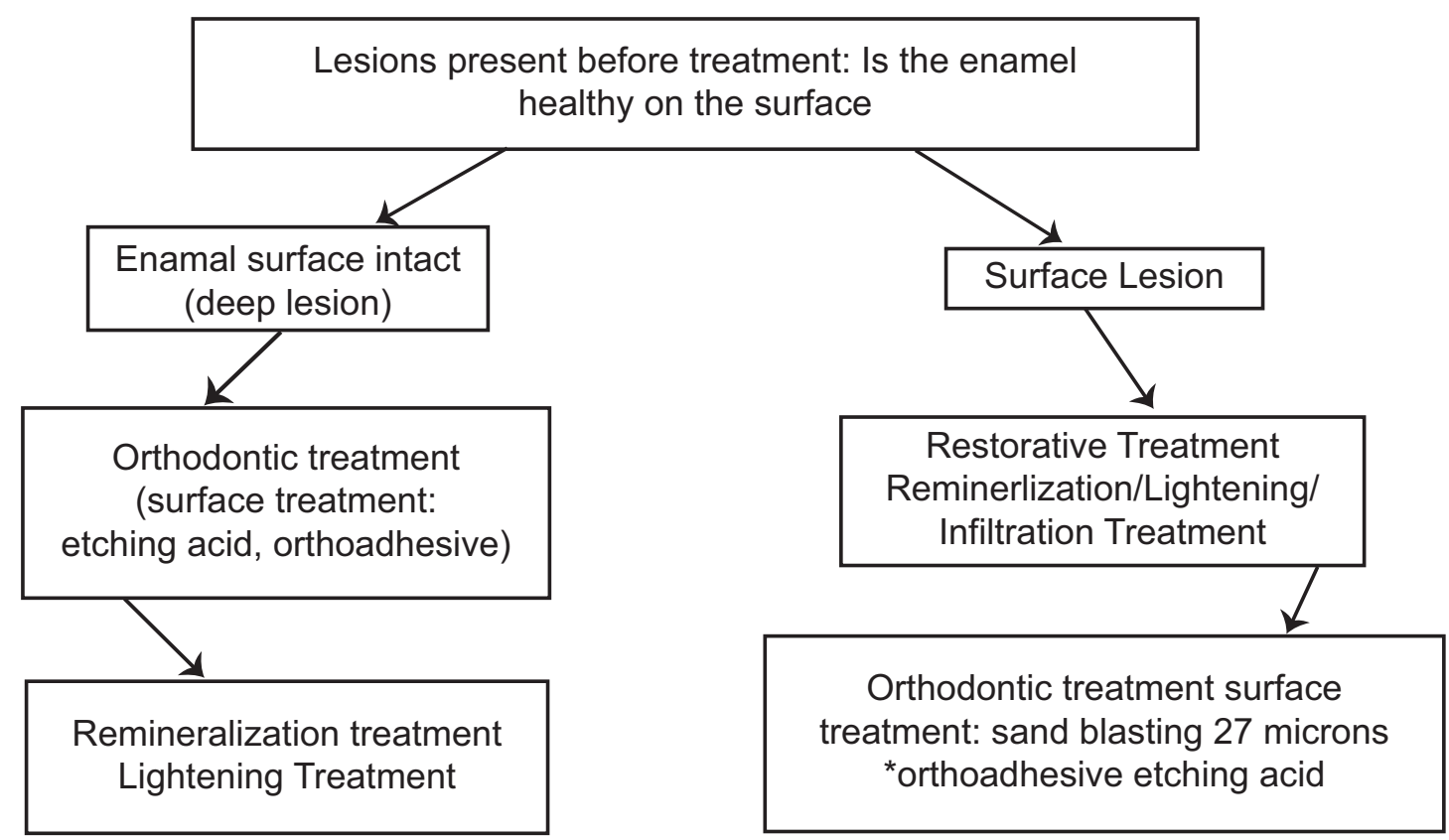

Figure 43

Decision tree: What if spots are visible and orthodontic treatment is indicated?

The second objective, regardless of the diagnosis, is to decrease the mechanical risk. Indeed, the hypomineralized enamel is less mechanically resistant than healthy enamel (clinical case no. 2, Figs. 14 and 15). Attaching a device directly to this area without specific pretreatment can be detrimental, especially when removing the fasteners: tearing may be at the expense of hypomineralized enamel and not within the bonding composite.

An infiltration treatment before orthodontic treatment is therefore recommended-it will not only strengthen the damaged enamel but also ensure good adhesion to the area. It has indeed been shown that the adhesion quality on hypomineralized and infiltrated enamel are the same as those on healthy ename $\left.\right|^{29,39}$

In the case of deep lesions, a concavity will have been created by the deep infiltration. This concavity is repaired using the composite. Adhesion in this area can be completed using a standard composite: sandblasting, adhesive, and bonding material.

However, in young patients with deep lesions, the surface enamel stays perfectly healthy and resilient. The problem is only esthetic. In the case of orthodontic care, it is better to wait until the orthodontic treatment is completed before taking care of the esthetic problem. To remove a stain then to attach a device to the area, even a ceramic device, can be a questionable approach (clinical case no. 4, Figs. 40-42).

\section{Spots have appeared during treat- ment (Clinical case \# 1:) Figs. 6-13 + Decision tree Fig. 44)}

If no lesions have been detected before the onset of orthodontic treatment, 


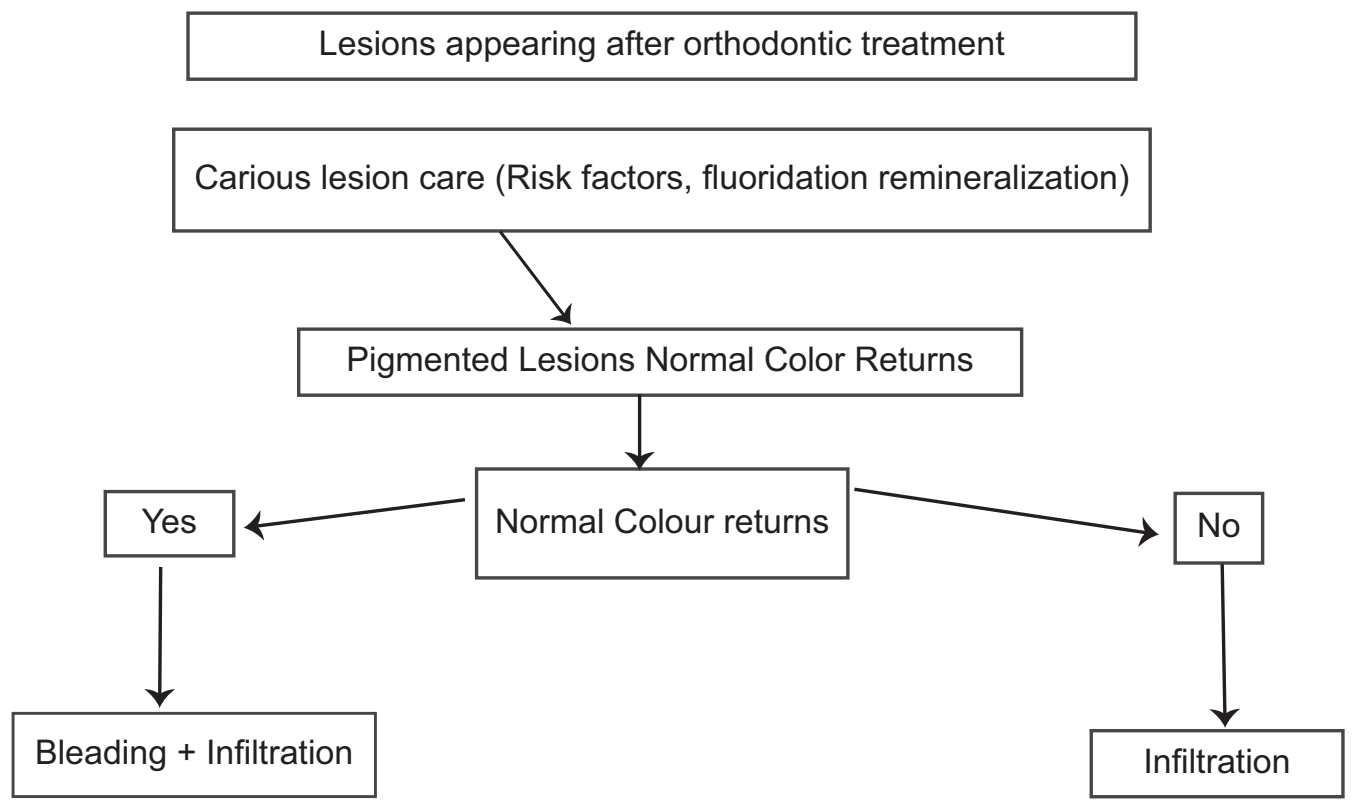

Figure 44

Decision Tree: What if spots have appeared during orthodontic treatment?

the visible spots after treatment are most likely early-stage carious lesions. A protocol to manage the carious process is therefore to be put in place, as well as a remineralization protocol. Unfortunately, as has already been mentioned, the effectiveness of these treatments is limited.
After 3 months of treatment, there is no more room for improvement.

The infiltration treatment is then indicated, associated or not with a prior lightening treatment.

\section{CONCLUSION}

The orthodontist is regularly confronted with the problem of enamel spots.

A few simple guidelines make it possible to reach the correct diagnosis in most cases.

The timing of the treatment is determined by observing the surfaces and possible substance losses at these spots.
In the case of spots detected before orthodontic treatment, the treatment is indicated before the placement of the device if the spots:

- reach the surface of the enamel;

- are associated with substance losses.

In other cases, their management can be carried out after orthodontic 
treatment without decreasing the chances of a good prognosis.

Prophylaxis and prevention are fundamental to orthodontic treatment. Unfortunately, they cannot guarantee the absence of spots at the end of treatment, even in compliant patients. In the case of postorthodontic spots, management may be offered to the patient. It consists of a combination of three treatments: remineralization, bleading, and infiltration.

These are simple, reproducible, easyto-implement treatments that present a particularly favorable benefit-stability relationship. They help to secure and optimize the orthodontic treatment.

Conflict of Interest: The authors declare that there is no conflict of interest.

\section{BIBLIOGRAPHY}

1. Atlan A, Denis M, Tirlet G, Attal J-P. L'érosion-infiltration, un nouveau traitement des taches blanches de l'émail. Clinic 2012;23-9.

2. Atlan A. Infiltration de l'émail hypominéralisé et mécanisme du masquage optique. Biomatériaux Clin 2016;1(1).

3. Attal J-P. Comment traiter toutes les taches de l'émail? Message $n^{\circ} 20$ : Le traitement ultra-conservateur des taches de l'émail : le protocole détaillé quel que soit l'étiologie. Le blog de Jean Pierre Attal. 2015.

4. Attal J-P, Atlan A, Denis M, Vennat E, Tirlet G. Nouveau concept pour le masquage des taches de l'émail. L'infiltration en profondeur - Partie III. Traitement d'une MIH sévère. Inf Dent 2014.

5. Attal J-P, Denis M, Atlan A, Vennat E, Tirlet G. L'infiltration en profondeur : un nouveau concept pour le masquage des taches de l'émail - Partie 1. Inf Dent 2013;(19):74-9.

6. Attal J-P, Atlan A, Denis M, Vennat E, Tirlet G. White spots on enamel: treatment protocol by superficial or deep infiltration (part 2). Int Orthod 2014;12(1):1-31.

7. Bailey $\mathrm{DL}$, et al. Regression of post-orthodontic lesions by a remineralizing cream. J Dent Res 2009;88(12):1148-53.

8. Belli R, Rahiotis C, Schubert EW, Baratieri LN, Petschelt A, Lohbauer U. Wear and morphology of infiltrated white spot lesions. J Dent 2011;39(5):376-85.

9. Benson PE, Parkin N, Millett DT, Dyer FE, Vine S, Shah A. Fluorides for the prevention of white spots on teeth during fixed brace treatment. Cochrane Database Syst Rev 2004;(3):CD003809.

10. Boushell LW. Nightguard vital bleaching: Side effects and patient satisfaction 10 to 17 years post-treatment. J Esthet Restor Dent 2012;24(3):211-9.

11. Chambers C, Stewart S, Su B, Sandy J, Ireland A. Prevention and treatment of demineralisation during fixed appliance therapy: a review of current methods and future applications. Br Dent J 2013;215(10):505-11.

12. Crombie F, Cochrane N, Manton D, Palamara J, Reynolds EC. Mineralisation of Developmentally Hypomineralised Human Enamel in vitro. Caries Res 2013;47(3):259-63.

13. Davila JM, Buonocore MG, Greeley CB, Provenza DV. Adhesive penetration in human artificial and natural white spots. J Dent Res 1975;54(5):999-1008. 
14. Denis M, Atlan A, Vennat E, Tirlet G, Attal J-P. White defects on enamel: diagnosis and anatomopathology: two essential factors for proper treatment (part 1). Int Orthod 2013;11(2):139-65.

15. Denis M, Atlan A, Vennat E, Tirlet G, Attal J-P. L'infiltration en profondeur: un nouveau concept pour le masquage des taches de l'émail - Partie 2. Traitement d'une fluorose sévère. Inf Dent 19:74-9.

16. Denis M, Atlan A, Vennat E. L'infiltration en profondeur. 2013.

17. Gorelick L, Geiger AM, Gwinnett AJ. Incidence of white spot formation after bonding and banding. Am J Orthod 1982;81(2):93-8.

18. Hadler-Olsen S, Sandvik K, El-Agroudi MA, Øgaard B. The incidence of caries and white spot lesions in ortho dontically treated adolescents with a comprehensive caries prophylactic regimen - a prospective study. Eur J Orthod 2012;34(5):633-9.

19. Haywood VB, Heymann H. Nightguard vital bleaching. Quintessence Int (Berl) 1989;(3):173-6.

20. Ismail $A$, et al. The International Caries Detection and Assessment System (ICDAS): an integrated system for measuring dental caries. Community Dent Oral Epidemiol 2007;35(3):170-8.

21. Kukleva M, Shetkova $D$, Beev VH. Comparative age study of the risk of demineralization during ortho dontic treatment with brackets. Folia Med (Plovdiv) 2002;44(1-2):56-9.

22. Magne P, Goldberg J, Edelhoff D, Güth JF. Composite Resin Core Buildups With and Without Post for the Restoration of Endodontically Treated Molars Without Ferrule. Oper Dent 2016;41(1);64-75.

23. Malek N, Alkhamis HA, Mesha S. The influence of resin infiltration system on enamel microhardness and sur face roughness : An in vitro study. Saudi Dent J. King Saud University 2012;24(2):79-84.

24. Marcusson A, Norevall LI, Persson M. White spot reduction when using glass ionomer cement for bon ding in orthodontics: a longitudinal and comparative study. Eur $\mathrm{J}$ Orthod 1997;19(3):233-42.

25. Mastroberardino S, Campus G, Strohmenger L, Villa A, Cagetti MG. An Innovative Approach to Treat Incisors Hypomineralization (MIH): A Combined Use of Casein PhosphopeptideAmorphous Calcium Phosphate and Hydrogen Peroxide - A Case Report. Case Rep Dent 2012;2012:379593.

26. Matis BA, Cochran MA, Eckert G. Review of the Effectiveness of Various Tooth Whitening Systems. Oper Dent 2009;34(2):230-5.

27. Meyer-Lueckel H, Paris S, Mueller J, Cölfen H, Kielbassa AM. Influence of the application time on the penetration of different dental adhesives and a fis sure sealant into artificial subsurface lesions in bovine enamel. Dent Mater 2006;22(1):22-8.

28. Meyer-Lueckel H, Bitter K, Paris S. Randomized controlled clinical trial on proximal caries infiltration: three-year follow-up. Caries Res 2012;46(6):544-8.

29. Naidu E, Stawarczyk B, Tawakoli PN, Attin R, Attin T, Wiegand A. Shear bond strength of orthodontic resins after caries infiltrant preconditioning. Angle Orthod 2013;83(2):306-12.

30. Ogaard B. White Spot Lesions During Orthodontic Treatment: Mechanisms and Fluoride Preventive Aspects. Semin Orthod 2008;14:183-93.

31. Paris S, Meyer-Lueckel H, Cölfen H, Kielbassa AM. Penetration coefficients of commercially available and experimental composites intended to infiltrate enamel carious lesions. Dent Mater 2007;23(6):742-8. 
32. Paris S, Bitter K, Naumann M, Dörfer CE, Meyer-Lueckel H. Resin infiltration of proximal caries lesions differing in ICDAS codes. Eur J Oral Sci 2011;119(2):182-6.

33. Paris $\mathrm{S}$, Meyer-Lueckel $\mathrm{H}$. Infiltrants inhibit progression of natural caries lesions in vitro. J Dent Res 2010;89(11):1276-80.

34. Paris S, Schwendicke F, Seddig S, Müller W-D, Dörfer C, Meyer-Lueckel H. Micro-hardness and mineral loss of enamel lesions after infiltration with various resins: influence of infiltrant composition and application frequency in vitro. J Dent 2013;41(6):543-8.

35. Paris $\mathrm{S}$, Meyer-Lueckel $\mathrm{H}$. Masking of labial enamel white spot lesions by resin infiltration-a clinical report. Quintessence Int 2009;40(9):713-8.

36. Shungin D, Olsson Al, Persson M. Orthodontic treatment related white spot lesions: A 14-year prospec tive quantitative follow-up, including bonding mate rial assessment. Am J Orthod Dentofacial Orthop 2010;138(2):136.e1-8.

37. Tirlet $\mathrm{G}$, Attal J. L'érosion/infiltration : une nouvelle thérapeutique pour masquer les taches blanche. L'information Dent 2011;26:2-7.

38. Torres CR, Rosa PC, Ferreira NS, Borges B. Effect of Caries Infiltration Technique and Fluoride Therapy on Microhardness of Enamel Carious Lesions. Oper Dent 2012;37(4):363-9.

39. Wiegand A, Stawarczyk B, Kolakovic M, Hämmerle CHF, Attin T, Schmidlin PR. Adhesive performance of a caries infiltrant on sound and demineralised enamel. J Dent 2011;39(2):117-21.

40. Willmot DR. White lesions after orthodontic treatment: does low fluoride make a difference? J Orthod 2004;31:235-42.

41. Yap J, Walsh LJ, Naser-Ud Din S, Ngo H, Manton DJ. Evaluation of a novel approach in the prevention of white spot lesions around orthodontic brackets. Aust Dent J 2014;59(1):70-80.

42. Zanolla J, Marques AB, da Costa DC, de Souza AS, Coutinho M. Influence of tooth bleaching on den tal enamel microhardness: a systematic review and meta-analysis. Aust Dent $J$ 2016; Dec (Ahead of print). 